\title{
Molecular Structure, Vibrational Spectra and Photochemistry of 2-Methyl-2H-Tetrazol-5-Amine in Solid Argon
}

\author{
A. Gómez-Zavaglia, ${ }^{\dagger, \downarrow}$ I. D. Reva, ${ }^{\dagger}$ L. Frija, ${ }^{\S}$ M. L. Cristiano, ${ }^{\S}$ and R. Fausto ${ }^{* \dagger \dagger}$ \\ Department of Chemistry, University of Coimbra, P-3004-535 Coimbra, Portugal, Faculty of Pharmacy and \\ Biochemistry, University of Buenos Aires, C.P. 1113 Buenos Aires, Argentina, and Department of Chemistry \\ and Biochemistry, University of Algarve, P-8005-139 Faro, Portugal
}

Received: April 6, 2005; In Final Form: June 6, 2005

\begin{abstract}
In this work, the molecular structure, infrared spectrum and UV photochemistry of 2-methyl-2H-tetrazol-5amine (2MTA) isolated in solid argon $(10 \mathrm{~K})$ were investigated. The experimental studies were supported by extensive DFT(B3LYP)/6-311++G(d,p) calculations. The infrared spectrum of matrix-isolated 2MTA was fully assigned and correlated with structural properties. Taking into consideration the observed frequency of the $\mathrm{NH}_{2}$ wagging mode, it is suggested that, in the matrixes, the amine group becomes slightly more planar than in the gas phase, due to matrix-packing effects. In situ UV irradiation $(\lambda>235 \mathrm{~nm})$ of the matrixisolated 2MTA monomer is shown to induce three main primary photochemical processes: (1) tautomerization to mesoionic 3-methyl-1H-tetrazol-3-ium-5-aminide; (2) nitrogen elimination, with production of 1-methyl$1 \mathrm{H}$-diazirene-3-amine; (3) ring cleavage leading to production of methyl azide and cyanamide. Following the primary photoproducts, secondary reactions were observed, leading to spectroscopic observation of methylenimine and isocyanidric acid.
\end{abstract}

\section{Introduction}

Tetrazole $\left(\mathrm{CN}_{4} \mathrm{H}_{2}\right)$ and its derivatives have been paid much attention due to their practical applications. The tetrazolic acid fragment, $-\mathrm{CN}_{4} \mathrm{H}$, has similar acidity and volume to the carboxylic acid group, $-\mathrm{CO}_{2} \mathrm{H}$, but is metabolically more stable. ${ }^{1}$ Hence, replacement of $-\mathrm{CO}_{2} \mathrm{H}$ groups by $-\mathrm{CN}_{4} \mathrm{H}$ groups in biologically active molecules is actually a research area of major interest. ${ }^{2}$ Indeed, the number of patent claims and publications related with medicinal uses of tetrazoles continues to grow rapidly and cover a wide range of applications: tetrazoles were found to exhibit antihypertensive, antiallergic, and antibiotic activity, ${ }^{3-5}$ and they are currently used, for example, as anticonvulsants ${ }^{6}$ and in cancer and AIDS treatments. ${ }^{7,8}$ Besides, tetrazoles also receive application in agriculture, as plant growth regulators, herbicides and fungicides, ${ }^{9}$ as stabilizers in photography and photoimaging ${ }^{10}$ and as gasgenerating agents for airbags. ${ }^{11}$

From a more fundamental point of view, tetrazoles are also particularly interesting molecules, because they have been shown to exhibit tautomerism ${ }^{12-23}$ and a very rich photochemistry. ${ }^{24-27}$

The parent compound of the tetrazole series, unsubstituted tetrazole, $\mathrm{CN}_{4} \mathrm{H}_{2}$, exhibits tautomerism. In the crystalline phases, tetrazole was found to exist exclusively as its $1 H$-tautomer. ${ }^{19-21}$ On the other hand, in solution, $1 \mathrm{H}$ - and $2 \mathrm{H}$ - tautomers coexist, the population of the most polar $1 H$ - form increasing with the polarity of the solvent, ${ }^{22,23}$ whereas in the gaseous phase the $2 \mathrm{H}$-tautomer constitutes ca. $90 \%$ of the total population at $90{ }^{\circ} \mathrm{C} .{ }^{15}$ In the case of substituted tetrazoles, tautomerism may also involve the substituent groups. For example, for the compound studied in this work, 2-methyl- $2 \mathrm{H}$-tetrazol-5-amine

\footnotetext{
* To whom all correspondence shall be addressed. E-mail: rfausto@ci.uc.pt

University of Coimbra.

$\doteqdot$ Universidad de Buenos Aires.

$\S$ University of Algarve.
}

(2MTA), amino/imino tautomerism can, in principle, occur (see Figure 1).

The photochemistry of tetrazole has been addressed in detail by Maier et al. ${ }^{26}$ Upon UV irradiation of matrix-isolated tetrazole, the main observed primary photoprocess was ring cleavage, leading to nitrogen elimination and production of nitrilimine, which then undergoes secondary photoreactions, such as isomerization to carbodiimide, cyanamide or a hydrogen cyanide/nitrene complex. ${ }^{26}$ Some substituted tetrazoles have also been studied regarding their photochemical fragmentation reactions. For these compounds, the nature of the substituents present in the tetrazole ring was found to strongly determine the final photoproducts. ${ }^{24,25,27}$ However, in general, as for unsubstituted tetrazole, the main reaction paths for their photochemical fragmentation have been found to result in nitrogen elimination or ring-cleavage (reverse [2+3] cycloaddition) leading to production of azides. ${ }^{24-27}$

When the substituent at the tetrazole ring carbon (at the 5 position) is an amino or imino group, photolysis can result in production of small $\mathrm{C}, \mathrm{N}$, and $\mathrm{H}$ containing molecules of important astrophysical and/or industrial interest (e.g., $\mathrm{CN}_{2} \mathrm{H}_{2}$, $\mathrm{CN}_{3} \mathrm{H}$ or $\mathrm{CNH}_{3}$ isomers). 2-Methyl-2H-tetrazol-5-amine (2MTA; see Figure 1) is one of the simplest molecules with these characteristics and was selected in the present work as a prototype species for studying the photochemistry as well as the structural (including tautomerism) and vibrational properties of this kind of molecules and their photoproducts. As the main experimental method, infrared spectroscopy, together with the technique of isolation of the compound in a low temperature inert matrix, was selected. The studied guest molecules do not rotate when they are embedded into a solid matrix host at low temperature (typically $10 \mathrm{~K}$ ). Additionally, when the matrix environment is inert (typically argon), the effects of inhomogeneous broadening of the vibrational bands are minimized. As a result, the vibrational bands in the spectra of matrix isolated 


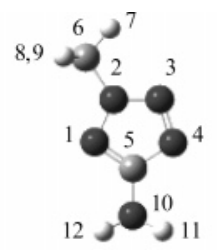

2-methyl-2H-tetrazol-5-amine
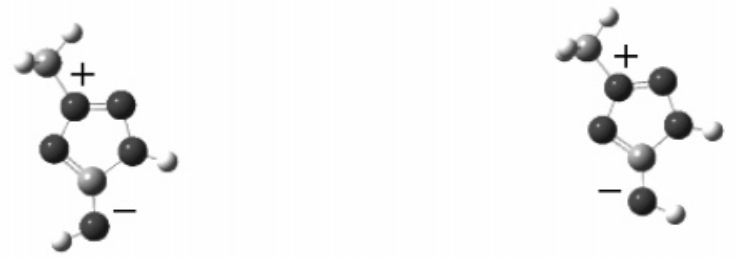

A

3-methyl-1 $H$-tetrazol-3-ium-5-aminide

B
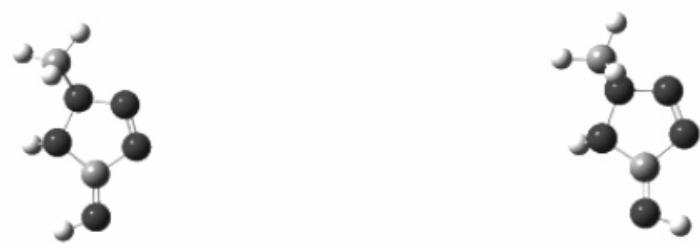

A

2-methyl-1,2-dihydro-5 $H$-tetrazol-5-imine
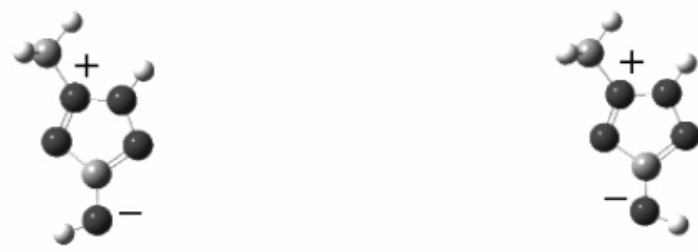

A

\section{2-methyl-3H-tetrazol-2-ium-5-aminide}

Figure 1. Calculated structures of 2-methyl-2H-tetrazol-5-amine (2MTA; with atom numbering) and of its imine (aminide) tautomers, 3-methyl-1 $H$-tetrazol-3-ium-5-aminide, 2-methyl-1,2-dihydro-5H-tetrazol-5-imine, and 2-methyl-3H-tetrazol-2-ium-5-aminide. In the case of the aminide tautomers, the placements of the charges on atoms correspond to one of the possible canonic forms for the mesoionic structures, which was also used to name the compound.

compounds become very sharp and narrow. Thus the main advantage of the matrix-isolation approach is the possibility to attain a considerably high spectroscopic resolution, which improves the probability to detect chemical species produced in low amounts during photolysis or those with intrinsically lowintensity IR absorptions. Further, due to the high resolution of the method, it is possible to distinguish spectral signatures of different tautomers or conformers, which are usually closely located in the spectrum (within a few wavenumbers). Next advantage, low temperature conditions can be used for trapping and spectroscopic identification of, at least, some of the intermediate transient products, which otherwise (e.g., at room temperature) are very reactive. Moreover, the fact that in a matrix the reactions are cage-confined (molecular diffusion is inhibited) introduces a useful simplification to the photochemistry, which under other experimental conditions might also involve a multitude of undesirable secondary processes. Finally, due to the high resolution of the method, it becomes possible to compare directly the experimental spectra with the results of theoretical calculations. In the present work, the interpretation of the experimental results was assisted by extensive high-level theoretical calculations.

\section{Materials and Methods}

Synthesis of 2MTA. A solution of sodium hydroxide (20\%) was added dropwise to a suspension of tetrazol-5-amino monohydrate $(10.3 \mathrm{~g} ; 0.1 \mathrm{~mol})$ in water $(30 \mathrm{~mL})$, with a drop of phenolphthalein. The mixture was stirred until complete dissolution of the suspended material. Dimethyl sulfate $(20 \mathrm{~mL}$; $0.11 \mathrm{~mol}$ ) was then added in small portions, keeping an alkaline medium through addition of aqueous sodium hydroxide. The final mixture was refluxed for $1 \mathrm{~h}$, then cooled, and filtered and the filtrate evaporated under reduced pressure to afford a solid residue. Water $(50 \mathrm{~mL})$ was added, and the mixture was then extracted with diethyl ether $(3 \times 50 \mathrm{~mL})$. The organic extract was dried over anhydrous sodium sulfate and filtered and the filtrate evaporated to afford a light yellow oil that slowly crystallized. Recrystallization from diethyl ether gave the desired compound as colorless needles (25\% yield; mp 376-377 K). ${ }^{1} \mathrm{H}$ NMR $\left(\mathrm{CDCl}_{3}\right): \delta 4.15(3 \mathrm{H}, \mathrm{s}) . \mathrm{MS}\left(\mathrm{CI} ; \mathrm{NH}_{3}\right): \mathrm{m} / z .100(\mathrm{M}$ $+\mathrm{H})^{+}, 117\left(\mathrm{M}+\mathrm{NH}_{4}\right)^{+}$.

Infrared Spectroscopy. The IR spectra were obtained using a Mattson (Infinity 60AR Series) Fourier Transform infrared spectrometer, equipped with a deuterated triglycine sulfate (DTGS) detector and a $\mathrm{Ge} / \mathrm{KBr}$ beam splitter, with $0.5 \mathrm{~cm}^{-1}$ resolution. Necessary modifications of the sample compartment of the spectrometer were done to accommodate the cryostat head and allow purging of the instrument by a stream of dry nitrogen to remove water vapors and $\mathrm{CO}_{2}$. A solid sample of 2MTA was placed in a specially designed doubly termostattable Knudsen cell. ${ }^{28}$ Both the sample container and valve nozzle compartments of this cell were kept at $90^{\circ} \mathrm{C}$ during deposition. Matrixes were prepared by co-deposition of $2 \mathrm{MTA}$ vapors coming out of the Knudsen cell together with large excess of the matrix gas (argon N60, obtained from Air Liquide) onto the CsI substrate of the cryostat cooled to $10 \mathrm{~K}$. Care was taken to keep the guest-to-host ratio in matrixes low enough to avoid association. All experiments were performed using an APD Cryogenics close-cycle helium refrigeration system with a DE202A expander.

Irradiation of the samples was carried out with a $150 \mathrm{~W}$ xenon arc lamp (Osram XBO 150W/CR OFR). No changes in the spectrum of the matrix-isolated 2MTA were observed during irradiation through a cutoff filter transmitting light above $337 \mathrm{~nm}$. However, irradiation of the matrixes through the outer $\mathrm{KBr}$ window of the cryostat $(\lambda>235 \mathrm{~nm})$ resulted in a series of photochemical transformations, as will be described below.

Computational Methodology. The quantum chemical calculations for 2MTA were performed with Gaussian 98 program package $^{29}$ at the DFT level of theory, using the $6-311++\mathrm{G}-$ $(d, p)$ basis set and the three-parameter density functional abbreviated as B3LYP, which includes Becke's gradient exchange correction ${ }^{30}$ and the Lee, Yang, Parr correlation functional. ${ }^{31}$ The calculations on the possible photoproducts were carried out at the same level of theory.

Geometrical parameters of the considered conformations were optimized using the Geometry Direct Inversion of the Invariant Subspace (GDIIS) method. ${ }^{32}$ To assist the analysis of the experimental spectra, vibrational frequencies and IR intensities were also calculated with the same basis set. The computed 
TABLE 1: Zero Point Vibrational Energy (ZPVE) Corrected DFT(B3LYP)/6-311++G(d,p) Calculated Energies $\left(E_{\mathrm{ZPVE}} /\right.$ Hartree$)$ and Relative Energies $\left(\Delta E_{\mathrm{ZPVE}} / \mathrm{kJ} \mathrm{mol}^{-1}\right)$, Including Zero Point Energy Corrections and Dipole Moments $(|\mu| /$ Debye) for 2MTA and Its 6 Imino/Aminide Tautomers

\begin{tabular}{lccc}
\hline & $E_{\mathrm{ZPVE}}$ & $\Delta E_{\mathrm{ZPVE}}$ & \\
\hline 2MTA & -352.945891 & 0.0 & 2.67 \\
3-methyl-1H-tetrazol-3-ium-5-aminide (A) & -352.906166 & $104.3(0.0)^{a}$ & 4.69 \\
3-methyl-1H-tetrazol-3-ium-5-aminide (B) & -352.899621 & $121.5(17.2)$ & 5.18 \\
2-methyl-1,2-dihydro-5H-tetrazol-5-imine (A) & -352.891460 & $142.9(38.6)$ & 6.22 \\
2-methyl-1,2-dihydro-5H-tetrazol-5-imine (B) & -352.897524 & $123.6(19.3)$ & 4.30 \\
2-methyl-3H-tetrazol-2-ium-5-aminide (A) & -352.855284 & $237.9(133.6)$ & 9.38 \\
2-methyl-3H-tetrazol-2-ium-5-aminide (B) & -352.855697 & $236.8(132.5)$ & 9.13
\end{tabular}

${ }^{a}$ In parentheses: relative energies for the imino/aminide tautomers of 2MTA taking as reference the lowest energy form.

harmonic frequencies were scaled down by a single factor $(0.978)$ to correct them for the effects of basis set limitations, neglected part of electron correlation and anharmonicity effects. Normal coordinate analysis was undertaken in the internal coordinates space, as described by Schachtschneider, ${ }^{33}$ using the program BALGA and the optimized geometries and harmonic force constants resulting from the DFT(B3LYP)/6$311++\mathrm{G}(\mathrm{d}, \mathrm{p})$ calculations.

\section{Results and Discussion}

2-Methyl-2H-tetrazol-5-amine (2MTA) can exhibit tautomerism associated with the amine substituent. Indeed, hydrogen shift from the amino group to three different positions of the tetrazole ring leads to three possible pairs of tautomers bearing an imine (or aminide) $\mathrm{NH}$ substituent at the position 5 (see Figure 1). Taking as reference the atom numbering of the tetrazole ring in 2MTA, the hydrogen involved in the tautomeric rearrangement can occupy the positions 1,3 , and 4 of the ring. In the first case tautomerism leads to the imine species, 2-methyl-1,2-dihydro-5H-tetrazol-5-imine, which can exist in two different conformations (A and B, in Figure 1), depending on the orientation of the imino hydrogen atom relative to the tetrazole ring. The remaining two cases lead to mesoionic-type structures, 2-methyl-3H-tetrazol-2-ium-5-aminide and 3-methyl$1 H$-tetrazol-3-ium-5-aminide, respectively, that may also exist in two different stable conformations (see Figure 1). Accordingly to the calculations, all these tautomers of 2MTA have relative energies higher than $100 \mathrm{~kJ} \mathrm{~mol}^{-1}$ (Table 1) and are not expected to be significantly populated in the gaseous phase, within the temperature range employed in this study $\left(<90{ }^{\circ} \mathrm{C}\right)$.

It is interesting to note that the relative energies of the six imine (aminide) possible tautomers of 2MTA shown in Figure 1 seem to be essentially determined by the repulsions between the methyl or imine (aminide) hydrogen atoms and the hydrogen atom directly connected to the tetrazole ring. The two conformers of both aminide tautomers were found to be nearly planar. The close proximity of the methyl and tetrazole-ring hydrogen atoms in 2-methyl-3H-tetrazol-2-ium-5-aminide justifies the considerably higher energy of this tautomer. For this compound, the two conformers have very similar energies due to the close resemblance of the two structures regarding intramolecular interactions (see Figure 1). On the other hand, the two conformers of 3-methyl-1H-tetrazol-3-ium-5-aminide differ in energy by $17.2 \mathrm{~kJ} \mathrm{~mol}^{-1}$, because in conformer A the repulsion between the aminide and tetrazole-ring hydrogen atoms is absent. The imine tautomer exhibits both $\mathrm{NH}$ and $\mathrm{NCH}_{3}$ nitrogen atoms pyramidalized $\left[\mathrm{N}-\mathrm{N}\left(-\mathrm{CH}_{3}\right)-\mathrm{N}\right.$ and $\mathrm{N}-\mathrm{N}(-\mathrm{H})-\mathrm{C}$ dihedral angles (defined as $\mathrm{X}-\mathrm{Y}(-\mathrm{A})-\mathrm{Z}$, where A stays outof-the-plane $\mathrm{X}-\mathrm{Y}-\mathrm{Z}$ ) were estimated by the calculations as +133.4 and $-124.3^{\circ}$, for conformer $\mathrm{A}$, and +136.3 and $-128.6^{\circ}$, for conformer $\left.\mathrm{B}\right]$. For this tautomer, the relative energies of the two conformers were also found to be influenced by the presence (in the less stable conformer A) or absence (in the more stable conformer B) of the repulsion between the imine and tetrazole-ring hydrogen atoms.

2MTA itself was found to have a planar tetrazole ring, with both the methyl carbon and amine nitrogen atoms lying in the ring-plane and the amine group pyramidalized [the calculated $\mathrm{H}-\mathrm{N}(-\mathrm{C})-\mathrm{H}$ dihedral angle was predicted to be $\left.135.9^{\circ}\right]$. One of the methyl hydrogens is also in the ring plane, with the $\mathrm{C}-\mathrm{H}$ bond eclipsing the $\mathrm{N} 2-\mathrm{N} 3$ bond, whereas the two remaining methyl hydrogen atoms occupy nearly symmetric positions above and below the plane of tetrazole ring. The complete equilibrium geometry of 2MTA is given in the Supporting Information Table S1.

IR Spectrum of the Matrix Isolated Compound (As Deposited Matrix). The IR spectrum of 2MTA isolated in solid argon is presented in Figure 2, together with the B3LYP/6$311++\mathrm{G}(\mathrm{d}, \mathrm{p})$ calculated spectrum. Despite most of the bands in the experimental spectrum exhibit splitting due to matrix site effects, the agreement between the experimental and calculated spectra is very good, enabling us to fully assign the bands on the basis of the theoretical data. The assignments are provided in Table 2 [results of vibrational calculations for 2MTA and its 6 imine (amidine) tautomers, including the definition of the used internal coordinates, are provided as Supporting Information Tables S2-S10]. The following additional remarks shall be made:

(a) No evidence of presence in the matrix of any of the imine (aminide) tautomers of MTA was found.

(b) The experimental spectrum contains minor bands due to traces of monomeric water, present in the system, which could not be avoided. However, it is clear from the positions of these bands $^{34}$ (see also Table 2) that water molecules were well isolated and do not interfere with the molecules of the compound under study.

(c) Among all calculated (scaled) frequencies for the minimum energy conformation, the one showing the largest relative deviation relative to the experimental value corresponds to the out-of-plane $\gamma \mathrm{NH}_{2}$ mode, which is ca. $25 \%$ overestimated by the calculations. Besides, the intensity of this band is also considerably overestimated. We investigated the dependence of the predicted spectra with the deviation of the amine group from planarity [the $\mathrm{H}-\mathrm{N}(-\mathrm{C})-\mathrm{H}$ dihedral angle was varied from $180.0^{\circ}\left(\mathrm{NH}_{2}\right.$ group planar) to $100.0^{\circ}$ ]. Note that in this particular case the calculated spectra for conformations other than the equilibrium one can still be considered meaningful because the $\gamma \mathrm{NH}_{2}$ vibration associated with change in the $\mathrm{H}-\mathrm{N}(-\mathrm{C})-\mathrm{H}$ dihedral angle couples significantly only with the $\delta \mathrm{NH}_{2}$ coordinate (see Table S3). For all nonequilibrium conformations, the forces coupling the out-of-plane $\gamma \mathrm{NH}_{2}$ with all other coordinates are negligible. Very interestingly, within the interval of variation considered, the spectrum practically did not change except in what concerns the frequency and IR intensity of the 


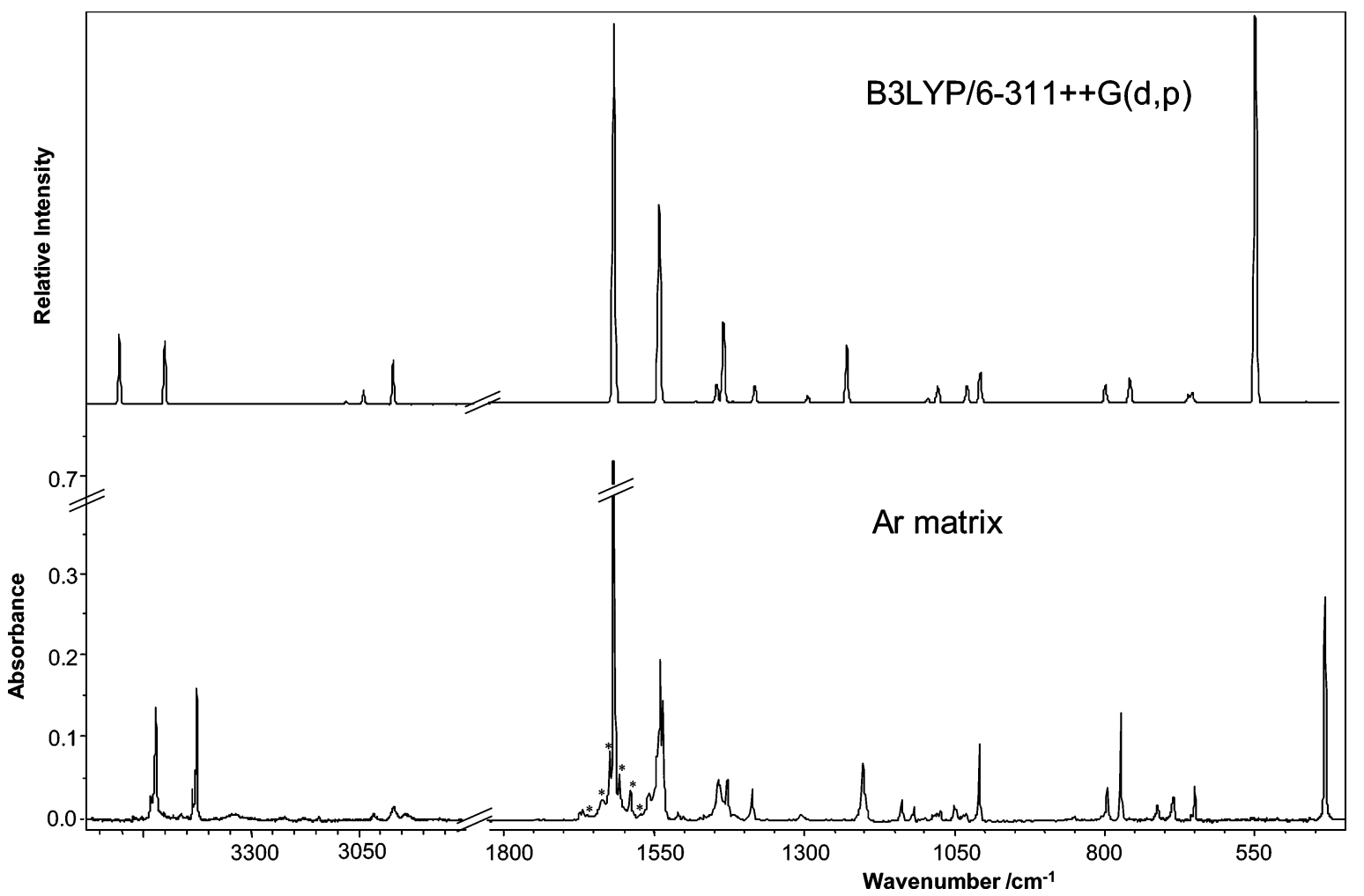

Figure 2. Infrared spectrum of $2 \mathrm{MTA}$ in argon matrix (as-deposited matrix) and DFT(B3LYP)/6-311+G(d,p) calculated infrared spectrum. In the experimental spectrum, the asterisks indicate bands due to traces of isolated monomeric water (see text). The calculated spectrum was simulated using Gaussian functions centered at the calculated frequency (scaled by 0.978 ) and with bandwidth-at-half-height equal to $5 \mathrm{~cm}^{-1}$.

$\gamma \mathrm{NH}_{2}$ mode. Indeed, this vibration is strongly affected by the geometry of the amine group, both its frequency and intensity reducing in going from less planar to more planar geometries (Figure 3). The calculated frequency matches the observed one for a $\mathrm{H}-\mathrm{N}(-\mathrm{C})-\mathrm{H}$ dihedral angle of $141.4^{\circ}\left(5.5^{\circ}\right.$ more than the value corresponding to the calculated minimum energy conformation; note that for this geometry, the energy was found to be only $0.395 \mathrm{~kJ} \mathrm{~mol}^{-1}$ higher than that of the minimum energy conformation). For this dihedral angle, the ratio of the calculated IR intensities of the two most intense bands in the spectrum $\left[I\left(\delta \mathrm{NH}_{2}\right) / I\left(\gamma \mathrm{NH}_{2}\right)\right]$ is $\sim 2$, close to the observed value of ca. 2.4, whereas the same ratio is calculated as nearly equal to unity for the minimum energy conformation. Hence, the data point to the occurrence of a change of geometry toward a more planar $\mathrm{NH}_{2}$ group upon isolation of the molecule of 2MTA in the argon matrix. Stabilization of more planar structures in matrixes (when compared with gas phase) is a relatively frequent phenomenon; it was observed previously, for example, for cyanoacetic acid and methyl cyanoacetate ${ }^{35,36}$ and benzil. ${ }^{37}$

UV Irradiation Experiments $(\lambda>235$ nm). To study the photochemistry of the matrix-isolated 2MTA, in situ UVirradiation $(\lambda>235 \mathrm{~nm})$ experiments were carried out. Upon irradiation, the bands due to 2MTA decrease in intensity, indicating that the compound is being transformed in other species, while new bands appear in the spectra. The changes are particularly noticeable in the $2300-1500 \mathrm{~cm}^{-1}$ spectral region, which is shown in Figure 4.

The photochemically induced opening of the tetrazole ring has been found to be an easy process. ${ }^{24-27,38-42}$ As mentioned in the Introduction, tetrazole itself easily eliminates molecular nitrogen, leading to production of nitrilimine, which then undergoes secondary photoreactions, such as isomerization to carbodiimide, cyanamide, or a hydrogen cyanide/nitrene com- plex. ${ }^{26}$ In the case of $2 \mathrm{MTA}$, the weakest bonds of the tetrazole ring are $\mathrm{N} 1-\mathrm{N} 2, \mathrm{~N} 2-\mathrm{N} 3$, and $\mathrm{N} 4-\mathrm{C} 5$, which correspond to the formal single bonds and can then be expected to undergo easier photochemical cleavage. Simultaneous cleavage of the $\mathrm{N} 1-\mathrm{N} 2$ and $\mathrm{N} 4-\mathrm{C} 5$ bonds (in a [2+3] cycloelimination) would lead to production of methyl azide and cyanamide, whereas the analogous reaction involving breakage of the $\mathrm{N} 2-\mathrm{N} 3$ and N4- C5 bonds might produce either the cyclic diazirene (1methyl-1H-diazirene-3-amine) or the open-ring nitrilimine (1methyl-nitrilimine-3-amine), with simultaneous release of molecular nitrogen. Finally, the simultaneous cleavage of N1-N2 and $\mathrm{N} 2-\mathrm{N} 3$ bonds would produce methyl nitrene and triazet4-amine.

The IR spectra of all the above-mentioned putative photoproducts were calculated and compared with the new bands observed in the spectra of the photolyzed matrix. Besides, available spectroscopic data for some of these species (methyl azide $^{43,44}$ and cyanamide ${ }^{45}$ ), were also taken into consideration. It was clear from these data that both cyanamide and methyl azide are among the photoproducts: the observed feature around $2260 \mathrm{~cm}^{-1}$ corresponds to the characteristic $v$ NCN antisymmetric stretching band originated in cyanamide, ${ }^{45}$ whereas methyl azide gives rise to the feature observed around 2100 $\mathrm{cm}^{-1}\left(v \mathrm{NNN}\right.$ antisymmetric stretching $\left.{ }^{43,44}\right)$. Other bands due to these two molecules expected to lie in the studied spectral range could also be identified in the spectra of the irradiated samples (a total of 9/13 bands for methyl azide and 5/6 bands for cyanamide; see Table 3), unequivocally demonstrating that simultaneous cleavage of the N1-N2 and N4-C5 bonds in the tetrazole ring of 2MTA took place upon irradiation. On the other hand, the feature appearing around $1815 \mathrm{~cm}^{-1}$ fits nicely the predicted frequency for the $v \mathrm{NCN}$ antisymmetric stretching vibration in 1-methyl-1H-diazirene-3-amine (see Figure 4 and Table 3). Indeed, it was possible to identify in the spectra of 
TABLE 2: Experimental and Calculated Wavenumbers and Intensities, and Potential Energy Distribution (PED) for 2-Methyl-2H-tetrazol-5-amine ${ }^{a}$

\begin{tabular}{|c|c|c|c|c|c|}
\hline \multirow[b]{2}{*}{$\begin{array}{c}\text { approximate } \\
\text { description }\end{array}$} & \multicolumn{2}{|c|}{ observed (Ar matrix) } & \multicolumn{3}{|c|}{ calculated [B3LYP/6-311++G(d,p)] } \\
\hline & $\begin{array}{c}\text { wavenumber } \\
\left(\mathrm{cm}^{-1}\right)\end{array}$ & $\begin{array}{c}\text { intensity } \\
{\text { (qualitative) })^{b}}^{\text {qua }}\end{array}$ & $\begin{array}{c}\text { wavenumber } \\
\left(\mathrm{cm}^{-1}\right)\end{array}$ & $\begin{array}{c}\text { intensity } \\
\left(\mathrm{km} \mathrm{mol}^{-1}\right)\end{array}$ & $\mathrm{PED}^{c}$ \\
\hline$v \mathrm{NH}_{2}$ as $+\gamma \mathrm{NH}_{2}$ & 3960.4 & $\mathrm{w}$ & & & \\
\hline$v \mathrm{NH}_{2} \mathrm{~s}+\gamma \mathrm{NH}_{2}$ & 3863.8 & w & & & \\
\hline \multirow[t]{3}{*}{$v \mathrm{H}_{2} \mathrm{O}$ (monomer) } & 3776.7 & $\mathrm{w}$ & & & \\
\hline & 3756.3 & $\mathrm{w}$ & & & \\
\hline & 3711.6 & $\mathrm{w}$ & & & \\
\hline \multirow[t]{3}{*}{$v \mathrm{NH}_{2}$ as } & 3533.0 & $\mathrm{w}$ & 3606.2 & 44.4 & $\mathrm{~S}_{28}(100.0)$ \\
\hline & 3523.7 & $\mathrm{~m} ; \mathrm{sh}$ & & & \\
\hline & 3520.9 & $\mathrm{~m}$ & & & \\
\hline \multirow[t]{3}{*}{$v \mathrm{NH}_{2} \mathrm{~S}$} & 3436.3 & w & 3503.8 & 40.1 & $\mathrm{~S}_{27}(99.9)$ \\
\hline & 3428.7 & $\mathrm{~m} ; \mathrm{sh}$ & & & \\
\hline & 3425.9 & $\mathrm{~m}$ & & & \\
\hline $2 \mathrm{x} \delta \mathrm{NH}_{2}$ & 3221.8 & vw & & & \\
\hline$\delta \mathrm{NH}_{2}+\nu \mathrm{C}=\mathrm{N}$ & 3143.7 & vw & & & \\
\hline$v \mathrm{CH}_{3}$ as' & 3015.2 & vw & 3095.6 & 1.1 & $\mathrm{~S}_{9}(97.2)$ \\
\hline$v \mathrm{CH}_{3}$ as"' & 2968.8 & vw & 3056.8 & 8.5 & $\mathrm{~S}_{10}(100.2)$ \\
\hline$\nu \mathrm{CH}_{3} \mathrm{~s}$ & 2940.5 & vw & 2990.4 & 27.4 & $\mathrm{~S}_{8}(97.0)$ \\
\hline $2 \mathrm{x} \omega \mathrm{NH}_{2}$ & 2212.2 & vw & & & \\
\hline$\nu \mathrm{N}-\mathrm{N} \mathrm{s}+\delta$ ring & 2069.1 & vw & & & \\
\hline \multirow[t]{2}{*}{$2 \mathrm{x} v \mathrm{~N}-\mathrm{N} \mathrm{s}$} & 2011.0 & vw & & & \\
\hline & 2007.8 & vw & & & \\
\hline \multirow[t]{2}{*}{$\nu \mathrm{C}=\mathrm{N}+\tau \mathrm{CH}_{3}$} & 1673.2 & vw & & & \\
\hline & 1669.4 & vw & & & \\
\hline \multirow[t]{3}{*}{$\delta \mathrm{H}_{2} \mathrm{O}$ (monomer) } & 1661.0 & vw & & & \\
\hline & 1637.5 & $\mathrm{w}$ & & & \\
\hline & 1624.6 & $\mathrm{~m}$ & & & \\
\hline \multirow[t]{2}{*}{$\delta \mathrm{NH}_{2}$} & 1618.0 & $\mathrm{~S} ; \mathrm{sh}$ & 1617.7 & 262.0 & $S_{16}(.3)+S_{1}(19.6)+S_{30}(18.0)$ \\
\hline & 1616.6 & $\mathrm{~S}$ & & & \\
\hline \multirow[t]{3}{*}{$\delta \mathrm{H}_{2} \mathrm{O}$ (monomer) } & 1607.9 & $\mathrm{~m}$ & & & \\
\hline & 1589.8 & w & & & \\
\hline & 1573.0 & $\mathrm{vW}$ & & & \\
\hline \multirow[t]{2}{*}{$2 \mathrm{x} v \mathrm{C}-\mathrm{N}\left(\mathrm{H}_{2}\right)$} & 1560.8 & $\mathrm{w}$ & & & \\
\hline & 1559.6 & $\mathrm{w} ; \mathrm{sh}$ & & & \\
\hline$\nu \mathrm{C}=\mathrm{N}$ & 1545.6 & $\mathrm{~m}$ & 1541.2 & 136.1 & $S_{6}(31.0)+S_{16}(26.0)+S_{1}(21.8)+S_{19}(9.6)$ \\
\hline & 1541.9 & $\mathrm{~m}$ & & & \\
\hline & 1539.9 & $\mathrm{~S}$ & & & \\
\hline & 1535.6 & $\mathrm{~m}$ & & & \\
\hline$\delta \mathrm{CH}_{3}$ as $^{\prime}$ & 1509.8 & $\mathrm{vw}$ & 1480.3 & 0.7 & $S_{12}(68.3)+S_{14}(15.6)$ \\
\hline & 1502.3 & $\mathrm{vw}$ & & & \\
\hline$\delta \mathrm{CH}_{3}$ as $^{\prime \prime}$ & 1449.5 & $\mathrm{w}$ & 1445.2 & 12.1 & $S_{13}(90.5)+S_{15}(9.6)$ \\
\hline$v \mathrm{~N}-\mathrm{C}$ & 1443.4 & $\mathrm{~m}$ & 1433.3 & 55.6 & $S_{5}(24.1)+S_{17}(17.2)+S_{12}(10.8)+S_{18}(9.8)+S_{4}(9.6)$ \\
\hline & 1440.7 & $\mathrm{w} ; \mathrm{sh}$ & & & \\
\hline & 1435.6 & $\mathrm{w} ; \mathrm{sh}$ & & & \\
\hline$\delta \mathrm{CH}_{3} \mathrm{~s}$ & 1428.6 & $\mathrm{w}$ & 1417.8 & 0.6 & $\mathrm{~S}_{11}(89.0)$ \\
\hline$v \mathrm{~N}-\mathrm{C}\left(\mathrm{H}_{3}\right)$ & 1391.7 & $\mathrm{vw}$ & & & \\
\hline & 1388.0 & vw; sh & 1381.4 & 11.6 & $S_{2}(38.9)+S_{20}(17.5)+S_{7}(16.1)+S_{3}(13.1)$ \\
\hline & 1386.0 & $\mathrm{~W}$ & & & \\
\hline$\tau$ ring $1+\delta$ ring 1 & 1325.0 & vw & & & \\
\hline$\nu \mathrm{N}-\mathrm{N}$ as & 1306.2 & $\mathrm{vw}$ & 1292.1 & 4.3 & $S_{3}(29.1)+S_{14}(22.8)+S_{7}(17.1)+S_{12}(10.2)$ \\
\hline & 1302.6 & vw & & & \\
\hline & 1298.8 & vw & & & \\
\hline$v \mathrm{~N}=\mathrm{N}$ & 1203.1 & $\mathrm{~m}$ & 1226.9 & 39.9 & $S_{4}(67.4)+S_{20}(19.4)$ \\
\hline & 1198.7 & w; sh & & & \\
\hline$\tau$ ring $1+\gamma \mathrm{NH}_{2}$ & 1137.8 & $\mathrm{w}$ & 1119.8 & $<0.1$ & $\mathrm{~S}_{15}(88.4)+\mathrm{S}_{13}(9.6)$ \\
\hline$\gamma \mathrm{CH}_{3}^{\prime \prime}$ & 1120.8 & $\mathrm{w} ; \mathrm{sh}$ & & & \\
\hline & 1118.0 & $\mathrm{w}$ & & & \\
\hline$\omega \mathrm{NH}_{2}$ & 1100.0 & vw & 1090.7 & 2.9 & $S_{17}(31.9)+S_{6}(35.8)+S_{19}(9.9)$ \\
\hline$\delta$ ring $1+\gamma \mathrm{NH}_{2}$ & 1086.1 & vw & & & \\
\hline & 1083.0 & vw & & & \\
\hline$\delta$ ring2 & 1079.8 & vw & 1073.8 & 11.4 & $S_{20}(20.4)+S_{17}(21.5)+S_{7}(12.6)+S_{19}(12.6)+S_{5}(14.1)$ \\
\hline & 1073.8 & vw & & & \\
\hline$\gamma \mathrm{CH}_{3}^{\prime \prime}$ & 1049.5 & $\mathrm{w}$ & 1025.2 & 11.8 & $S_{14}(50.3)+S_{3}(21.1)+S_{7}(11.4)$ \\
\hline$\tau$ ring $1+\gamma$ ring 1 & 1035.2 & vw & & & \\
\hline & 1030.7 & vw & & & \\
\hline$\nu \mathrm{N}-\mathrm{N} \mathrm{s}$ & 1013.9 & vw & 1002.7 & 20.4 & $S_{7}(23.9)+S_{5}(38.6)+S_{19}(10.5)+S_{3}(10.3)$ \\
\hline & 1010.1 & $\mathrm{w}$ & & & \\
\hline & 1008.4 & $\mathrm{~m}$ & & & \\
\hline
\end{tabular}




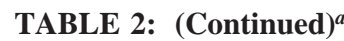

\begin{tabular}{|c|c|c|c|c|c|}
\hline \multirow[b]{2}{*}{$\begin{array}{l}\text { approximate } \\
\text { description }\end{array}$} & \multicolumn{2}{|c|}{ observed (Ar matrix) } & \multicolumn{3}{|c|}{ calculated [B3LYP/6-311++G(d,p)] } \\
\hline & $\begin{array}{l}\text { wavenumber } \\
\left(\mathrm{cm}^{-1}\right)\end{array}$ & $\begin{array}{c}\text { intensity } \\
\text { (qualitative) }^{b}\end{array}$ & $\begin{array}{l}\text { wavenumber } \\
\left(\mathrm{cm}^{-1}\right)\end{array}$ & $\begin{array}{l}\text { intensity } \\
\left(\mathrm{km} \mathrm{mol}^{-1}\right)\end{array}$ & $\mathrm{PED}^{c}$ \\
\hline $2 \mathrm{x} \gamma \mathrm{NH}_{2}$ & 851.0 & vw & & & \\
\hline$\nu \mathrm{C}-\mathrm{N}\left(\mathrm{H}_{2}\right)$ & $\begin{array}{l}797.6 \\
795.6\end{array}$ & $\begin{array}{l}\mathrm{w} ; \mathrm{sh} \\
\mathrm{m}\end{array}$ & 792.6 & 12.2 & $\mathrm{~S}_{1}(22.0)+\mathrm{S}_{19}(24.5)+\mathrm{S}_{2}(19.7)+\mathrm{S}_{20}(14.2)$ \\
\hline$\tau$ ring2 & 772.5 & $\mathrm{~S}$ & 751.4 & 16.7 & $\mathrm{~S}_{24}(53.2)+\mathrm{S}_{22}(40.2)$ \\
\hline$\omega \mathrm{N}-\left(\mathrm{CH}_{3}\right)+\gamma \mathrm{NH}_{2}$ & $\begin{array}{l}712.6 \\
711.6\end{array}$ & $\begin{array}{l}\text { w } \\
\text { w; sh }\end{array}$ & & & \\
\hline$\tau$ ring1 & $\begin{array}{l}690.0 \\
685.6\end{array}$ & $\begin{array}{l}\mathrm{vw} ; \mathrm{sh} \\
\mathrm{w}\end{array}$ & 653.2 & 5.2 & $\mathrm{~S}_{23}(98.2)$ \\
\hline$\delta$ ring1 & $\begin{array}{l}655.6 \\
653.4 \\
651.5 \\
650.1\end{array}$ & $\begin{array}{l}\mathrm{vw} \\
\mathrm{vW} \\
\mathrm{vw} ; \mathrm{sh} \\
\mathrm{w}\end{array}$ & 646.6 & 6.2 & $\mathrm{~S}_{19}(20.1)+\mathrm{S}_{2}(32.7)+\mathrm{S}_{1}(12.8)+\mathrm{S}_{20}(11.8)$ \\
\hline$\gamma \mathrm{NH}_{2}$ & 433.2 & S & 540.8 & 267.5 & $\mathrm{~S}_{30}(71.2)+\mathrm{S}_{16}(18.4)$ \\
\hline$\omega \mathrm{C}-\left(\mathrm{NH}_{2}\right)$ & n.i. & & 455.2 & 0.6 & $\mathrm{~S}_{18}(51.9)+\mathrm{S}_{26}(35.9)$ \\
\hline$\gamma$ ring1 & & & 340.5 & 8.4 & $S_{22}(43.6)+S_{24}(30.3)+S_{25}(19.7)$ \\
\hline $\mathrm{tNH}_{2}$ & & & 310.7 & 2.7 & $\mathrm{~S}_{29}(51.8)+\mathrm{S}_{18}(10.7)+\mathrm{S}_{26}(27.1)$ \\
\hline$\omega \mathrm{N}-\left(\mathrm{CH}_{3}\right)$ & & & 279.2 & 28.1 & $\mathrm{~S}_{26}(24.1)+\mathrm{S}_{29}(42.9)+\mathrm{S}_{18}(23.6)$ \\
\hline$\gamma$ ring2 & & & 173.7 & 8.6 & $S_{25}(82.3)+S_{22}(9.7)+S_{24}(9.7)$ \\
\hline$\tau \mathrm{CH}_{3}$ & & & 103.8 & $<0.1$ & $\mathrm{~S}_{21}(100.9)$ \\
\hline
\end{tabular}

${ }^{a}$ Bands due to traces of isolated $\mathrm{H}_{2} \mathrm{O}$ monomer were also observed in the as-deposited matrix. The corresponding wavenumbers are also provided in this table. Key: $\nu$, stretching; $\delta$, bending; $\gamma$, rocking; $\omega$, wagging; $\tau$, torsion; s., symmetric; as., asymmetric. Proposed assignments for overtones and combination tones shall be considered as tentative. ${ }^{b}$ Key: s, strong; m, medium; w, weak; vw, very weak; b, broad; sh, shoulder. ${ }^{c}$ See Table S2 (Supporting Information) for definition of coordinates. Only PED values greater than $9.5 \%$ are given.

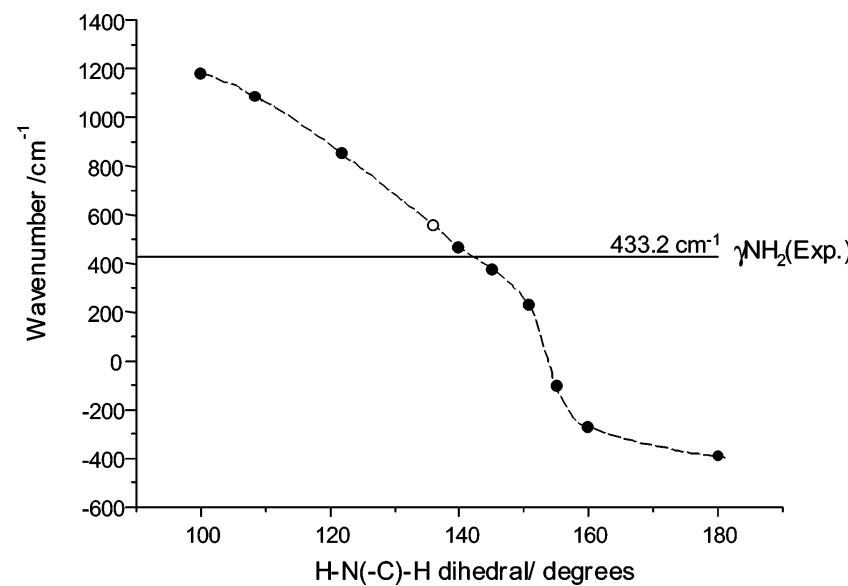

Figure 3. Dependence of the DFT(B3LYP)/6-311++G(d,p) calculated (scaled by 0.978) $\gamma \mathrm{NH}_{2}$ wavenumber on the $\mathrm{H}-\mathrm{N}(\mathrm{C})-\mathrm{H}$ dihedral angle (which is a measure of the degree of planarity of the amine group). The open circle corresponds to the minimum energy structure. Imaginary wavenumbers are represented by negative values.

the irradiated matrix 11 out of the 14 bands of this species expected to lie in the studied spectral range (see Table 3). Hence, nitrogen elimination through simultaneous cleavage of the N2$\mathrm{N} 3$ and N4-C5 bonds did also occur, with production of the cyclic diazirine. No bands ascribable to the ring-open nitrilimine $\left(\mathrm{CH}_{3}-\mathrm{N}=\mathrm{N}^{+}=\mathrm{C}^{-}-\mathrm{NH}_{2}\right)$ were observed, nor those ascribable to the products of the simultaneous cleavage of $\mathrm{N} 1-\mathrm{N} 2$ and $\mathrm{N} 2-\mathrm{N} 3$ bonds (methyl nitrene and triazet-4-amine). This last result indicates that if simultaneous cleavage of N1-N2 and $\mathrm{N} 2-\mathrm{N} 3$ bonds occurs, the primary photoproducts must undergo fast subsequent reactions. In this case, the most probable final products would be methylenimine, resulting from rearrangement of methyl nitrene, and cyanamide $+\mathrm{N}_{2}$, resulting from opening of the four-membered ring of triazet-4-amine. We shall return to this point later on.

Besides the above-mentioned primary photoproducts, generation of other species upon irradiation of the matrix could also be established from the analysis of the spectra of the photolyzed matrix. Two of these species are methyleninime and CNH. In the case of methylenimine, all but the $v \mathrm{NH}$ stretching vibration (predicted by the calculations as a very low intensity band $1.59 \mathrm{~km} \mathrm{~mol}^{-1}$ ) were identified (see Table 3 ). In the 2300$1500 \mathrm{~cm}^{-1}$ spectral region (see Figure 4) methylenimine gives rise to the band observed at $1649.5 \mathrm{~cm}^{-1}$, ascribable to $\nu \mathrm{CN}$. On the other hand, both the $v \mathrm{NH}$ and $v \mathrm{CN}$ bands of $\mathrm{CNH}$ were observed, the first at ca. $3580 \mathrm{~cm}^{-1}$ and the second around 2030 $\mathrm{cm}^{-1}$ (see Figure 4). The origin of these two products can be easily explained: it is well-known that UV-induced decomposition of matrix isolated methyl azide gives rise to molecular nitrogen and methylenimine, through a concerted motion of $\mathrm{N}_{2}$ elimination with hydrogen shift; ${ }^{44,46,47}$ on the other hand, methylenimine can give $\mathrm{CNH}$ by $1,1-\mathrm{H}_{2}$ elimination, which was found to be a preferred route compared to $1,2-\mathrm{H}_{2}$ elimination giving $\mathrm{HCN}, 1,2-\mathrm{H}$ shift yielding aminocarbene and $\mathrm{N}-\mathrm{H}$ bond cleavage leading to the $\mathrm{H}_{2} \mathrm{CN}$ radical. ${ }^{46}$ Another source of methylenimine (and, consequently, also of $\mathrm{CNH}$ ) can be the photodecomposition of the primarily formed diazirine, which can undergo a ring-opening photoreaction leading to methylenimine and cyanamide, and the above-mentioned simultaneous cleavage of the N1-N2 and N2-N3 bonds of 2MTA. In these two cases, methyl nitrene shall act as intermediate. Note that the second putative primary photoproduct of simultaneous cleavage of the $\mathrm{N} 1-\mathrm{N} 2$ and $\mathrm{N} 2-\mathrm{N} 3$ bonds of $2 \mathrm{MTA}$, triazet4-amine, can be expected also to undergo subsequent photolysis, leading to elimination of molecular nitrogen and formation of cyanamide. Hence, the occurrence of this process cannot be stated without any doubt, because its expected final products can also be obtained through other reaction paths (which could be firmly established by identification of species that can only be produced in a unique way), and both putative primary photoproducts (methyl nitrene and triazet-4-amine) could not be identified spectroscopically.

Ring-opening processes involving breakage of only one single bond were also investigated. Among them, cleavage of the $\mathrm{N} 2-\mathrm{N} 3$ bond would lead to 1-diazo-1-[methyldiazenyl]methanamine $\left(\mathrm{CH}_{3}-\mathrm{N}=\mathrm{N}-\mathrm{C}\left(\mathrm{NH}_{2}\right)=\mathrm{N}^{+}=\mathrm{N}^{-}\right)$, which was predicted 


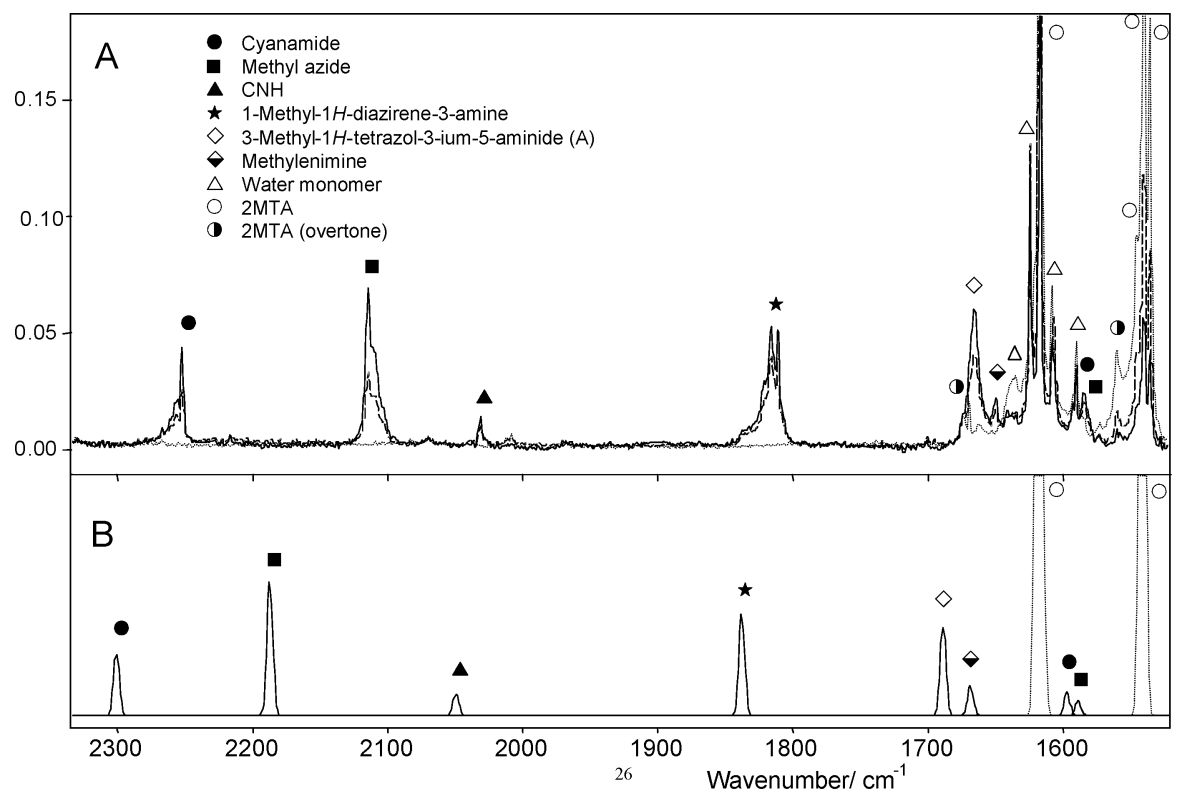

Figure 4. (A) $2300-1500 \mathrm{~cm}^{-1}$ region of the infrared spectra of the as-deposited argon matrix of 2MTA (dotted line) and of the UV-irradiated $(\lambda>235 \mathrm{~nm}$ ) matrix after $80 \mathrm{~min}$ (dashed line) and $160 \mathrm{~min}$ (solid line) of irradiation. (B) DFT(B3LYP)/6-311++G(d,p) calculated (scaled by 0.978) infrared spectra of 2MTA and photoproducts in the same spectral region. In the calculated spectra, intensities for each molecule were scaled by different factors, to approximately simulate the corresponding observed intensities in the spectrum of the as-deposited matrix (2MTA) or of the 160 min irradiated matrix (all products). Ordinate scale of the experimental spectra in units of absorbance.

to give rise to an intense band $(\nu \mathrm{C}=\mathrm{N}=\mathrm{N}$ antisymmetric stretching) at $2113 \mathrm{~cm}^{-1}$ (intensity: $535.6 \mathrm{~km} \mathrm{~mol}^{-1}$ ). This vibration could also contribute to the band experimentally observed at $2031 \mathrm{~cm}^{-1}$, ascribed to $\mathrm{CNH}$ (Table 3). Unfortunately, all other vibrations of the methanamine were predicted by the calculations as giving rise to weak infrared bands. Hence, the possibility of occurrence of this process cannot be ruled out nor confirmed.

An additional photoproduct could also be identified in the spectra of the irradiated matrix: conformer A of the 2MTA aminide tautomer, 3-methyl- $1 H$-tetrazol-3-ium-5-aminide (see Figure 1), which can be obtained from 2MTA through 1,3-H shift. In the $2300-1500 \mathrm{~cm}^{-1}$ spectral region, this species gives rise to the band at $1664.1 \mathrm{~cm}^{-1}$ (see Figure 4), but on the whole, 11 out of the 28 bands of this species expected to lie in the studied spectral range were identified (see Table 3 ). Note that, as already mentioned in this paper, this is the lowest energy imine/aminide tautomer of 2MTA and, besides, once formed it shall be comparatively less reactive to photolysis because $\mathrm{N}_{2}$ elimination would also require an additional hydrogen atom migration. Furthermore, among the six possible imine/aminide tautomers, it is one of the two forms that can be directly produced from 2MTA as a result of an energetically accessible hydrogen shift. The other is conformer B of 2-methyl-1,2-dihydro-5H-tetrazol-5-imine, which was not identified as contributing to the spectra of the irradiated matrix (this form is less stable than the observed species by ca. $20 \mathrm{~kJ} \mathrm{~mol}^{-1}$ and has a nonplanar structure, then requiring a more important rearrangement of the matrix; see Figure 1 and Table 1). The 1,4-H shift appears as an improbable process for the matrix isolated molecule and, thus, both conformers of 3-methyl-1H-tetrazol-3-ium-5-aminide are not expectable products (these are also the less stable among the 6 imine/ aminide tautomers of 2MTA; see Table 1). On the other hand, both conformer B of 3-methyl-1H-tetrazol-3-ium-5-aminide and conformer A of 2-methyl-1,2-dihydro-5H-tetrazol-5-imine have the wrong geometry for $1,3-\mathrm{H}$ shift, requiring either an additional 180 degrees rotation about the $\mathrm{C}-\mathrm{N}(\mathrm{H})$ bond or lateral migration of the imine (aminide) hydrogen atom, and its production is not expected either to be a favored process in a matrix.

In summary, as depicted in Figure 5, photolysis of matrixisolated 2MTA leads to (1) nitrogen elimination, with production of 1-methyl-1H-diazirene-3-amine; (2) ring cleavage leading to production of methyl azide and cyanamide; and (3) tautomerization to mesoionic 3-methyl- $1 H$-tetrazol-3-ium-5-aminide in the A conformation. Following the primary photoproducts, secondary reactions were observed, leading to spectroscopic observation of methylenimine and isocyanidric acid. Photochemical ring-opening leading to methyl nitrene and triazet-4amine as primary photoproducts cannot also be discarded, but no firm evidence of this process could be established.

Two additional points deserve here further comments. The first results from the fact that in a matrix reactions are cage confined. Hence, these processes lead, necessarily, to production of species that, once produced in the same matrix cage, shall interact with each other to some extent. In the present case, the precise nature of these interactions is not easily accessible, because up to four molecular species might coexist in the same cage (e.g., cyanamide $+\mathrm{CNH}+\mathrm{H}_{2}+\mathrm{N}_{2}$ ). However, their importance is clearly reflected in the fact that in many cases, the observed frequencies for the photoproducts do not exactly match the reference frequencies for the isolated monomeric species in the same experimental conditions (see Table 3 ). The second point relates with the kinetics of the different processes observed. It can easily be concluded, from Figure 6, which shows the change in the integral intensities (normalized by the corresponding calculated intensities) of characteristic bands of the various observed photoproducts with time of irradiation, that different products are formed at different rates and in different amounts. Among the three primary photoprocesses, nitrogen elimination with formation of 1-methyl- $1 H$-diazirene-3-amine is the fastest reaction. The 1-methyl- $1 H$-diazirene-3-amine subsequent photodecomposition (to cyanamide and methylenimine) is also a comparatively fast process, because after 180 min of irradiation the change in the amount of 1-methyl- $1 H$ - 
TABLE 3: Assignments for the Infrared Bands Due to Photoproducts Resulting from UV Irradiation $(\lambda>235 \mathrm{~nm})$ of $2 \mathrm{MTA}$ Isolated in Solid Argon

\begin{tabular}{|c|c|c|c|c|}
\hline \multirow[b]{2}{*}{ assignment } & \multirow{2}{*}{$\begin{array}{l}\text { approximate } \\
\text { description }\end{array}$} & \multicolumn{3}{|c|}{ wavenumber $\left(\mathrm{cm}^{-1}\right)$} \\
\hline & & observed & calculated $^{b}$ & reference $^{c}$ \\
\hline $\mathrm{CNH}$ & $v \mathrm{~N}-\mathrm{H}$ & $\begin{array}{l}3580.1 \\
3576.8\end{array}$ & $3724.0(371)$ & 3653 \\
\hline \multirow{3}{*}{$\begin{array}{l}\text { 1-methyl-1H-diazirene-3-amine } \\
\text { 3-methyl-1H-tetrazol-3-ium-5-aminide (A) } \\
\text { cyanamide }\end{array}$} & $v \mathrm{NH}_{2}$ as. & 3536.0 & $3598.3(52)$ & \multirow{4}{*}{3498} \\
\hline & $v \mathrm{~N}-\mathrm{H}_{(12)}$ & & $3588.8(118)$ & \\
\hline & $v \mathrm{NH}_{2}$ as. & 3528.1 & $3568.0(70)$ & \\
\hline \multirow{2}{*}{$\begin{array}{l}\text { 1-methyl-1H-diazirene-3-amine } \\
\text { cyanamide }\end{array}$} & $v \mathrm{NH}_{2} \mathrm{~s}$ & 3445.0 & $3489.5(39)$ & \\
\hline & $v \mathrm{NH}_{2} \mathrm{~s}$ & 3432.7 & $3477.1(44)$ & 3401 \\
\hline \multirow{2}{*}{$\begin{array}{l}\text { methylenimine } \\
\text { methyl azide }\end{array}$} & $\nu \mathrm{CH}_{2}$ as. & 3084.8 & $3044.4(32)$ & 3036 \\
\hline & $v \mathrm{CH}_{3}$ as." & 2995.9 & $3001.7(31)$ & 2973 \\
\hline 1-methyl- $1 H$-diazirene-3-amine & $\nu \mathrm{CH}_{3}$ as." & 2951.2 & $2996.2(22)$ & \\
\hline methyl azide & $v \mathrm{CH}_{3} \mathrm{~s}$ & 2922.9 & $2945.0(49)$ & 2937 \\
\hline methylenimine & $v \mathrm{CH}_{2} \mathrm{~s}$. & & $2945.7(53)$ & 2926 \\
\hline 1-methyl- $1 H$-diazirene-3-amine & $v \mathrm{CH}_{3} \mathrm{~s}$ & 2896.9 & $2933.0(39)$ & \\
\hline cyanamide & $v \mathrm{NCN}$ as. & 2265.8 & $2300.1(126)$ & 2264 \\
\hline & & 2260.4 & & \\
\hline & & 2255.7 & & \\
\hline & & 2251.8 & & \\
\hline methyl azide & $\nu \mathrm{NNN}$ as. & 2114.0 & $2186.8(553)$ & 2100 \\
\hline & & 2110.4 & & \\
\hline & & 2108.8 & & \\
\hline & & 2104.2 & & \\
\hline $\mathrm{CNH}$ & $\nu \mathrm{CN}$ & 2031.2 & $2049.2(74)$ & 2024 \\
\hline & & 2026.0 & & \\
\hline 1-methyl-1H-diazirene-3-amine & $v \mathrm{NCN}$ as. & 1820.8 & $1837.7(280)$ & \\
\hline & & 1815.9 & & \\
\hline & & 1810.4 & & \\
\hline 3-methyl-1H-tetrazol-3-ium-5-aminide (A) & $v \mathrm{C}-\mathrm{N}\left(\mathrm{H}_{(11)}\right)$ & 1664.1 & $1680.9(721)$ & \\
\hline methylenimine & $v \mathrm{CN}$ & 1649.5 & $1668.6(25)$ & 1641 \\
\hline cyanamide & $\delta \mathrm{NH}_{2}$ & 1584.6 & $1596.9(48)$ & 1586 \\
\hline 1-methyl- $1 H$-diazirene-3-amine & $\delta \mathrm{NH}_{2}$ & & $1588.8(42)$ & \\
\hline 1-methyl- $1 H$-diazirene-3-amine & $\delta \mathrm{CH}_{3}$ as.' & 1466.0 & $1466.5(10)$ & \\
\hline methyl azide & $\delta \mathrm{CH}_{3}$ as.' $^{\prime}$ & 1458.0 & $1459.6(19)$ & 1448 \\
\hline methylenimine & $\delta \mathrm{CH}_{2}$ & & $1459.5(7)$ & 1453 \\
\hline 1-methyl- $1 H$-diazirene-3-amine & $\delta \mathrm{CH}_{3}$ as." & 1435.6 & $1439.1(7)$ & \\
\hline methyl azide & $\delta \mathrm{CH}_{3} \mathrm{~s}$. & 1415.2 & $1419.8(7)$ & 1405 \\
\hline 3-methyl-1H-tetrazol-3-ium-5-aminide (A) & $\delta \mathrm{CH}_{3} \mathrm{~s}$. & & $1413.2(8)$ & \\
\hline 1-methyl-1H-diazirene-3-amine & $\delta \mathrm{CH}_{3} \mathrm{~s}$. & 1406.9 & $1406.1(2)$ & \\
\hline 3-methyl-1H-tetrazol-3-ium-5-aminide (A) & $\delta \mathrm{NH}_{(12)}$ & 1388.8 & $1370.6(27)$ & \\
\hline 1-methyl-1H-diazirene-3-amine & $v \mathrm{NCN}$ s. & 1375.2 & $1355.5(64)$ & \\
\hline & & 1371.3 & & \\
\hline 3-methyl-1H-tetrazol-3-ium-5-aminide (A) & $v \mathrm{~N}_{(1)}-\mathrm{N}_{(2)}$ & 1359.2 & $1360.4(37)$ & \\
\hline methylenimine & $\delta \mathrm{NH}$ & 1357.6 & $1340.8(35)$ & 1348 \\
\hline 3-methyl-1H-tetrazol-3-ium-5-aminide (A) & $\mathrm{dN}-\mathrm{H}_{(11)}$ & 1305.1 & $1299.9(67)$ & \\
\hline methyl azide & $v$ NNN s. & 1277.3 & $1310.3(132)$ & 1270 \\
\hline & & 1272.9 & & \\
\hline & & 1261.5 & & \\
\hline 3-methyl-1H-tetrazol-3-ium-5-aminide (A) & $v \mathrm{~N}_{(3)}-\mathrm{N}_{(4)}$ & 1160.6 & $1154.4(75)$ & \\
\hline methylenimine & $\gamma \mathrm{NH}$ & 1113.1 & $1136.3(47)$ & 1123 \\
\hline methyl azide & $\gamma \mathrm{CH}_{3}^{\prime}$ & & $1121.5(12)$ & 1125 \\
\hline methylenimine & $\gamma \mathrm{CH}_{2}$ & 1071.9 & $1079.8(18)$ & 1063 \\
\hline cyanamide & $v \mathrm{NCN}$ s. & 1067.8 & $1072.3(10)$ & 1061 \\
\hline methylenimine & $\omega \mathrm{CH}_{2}$ & 1040.2 & $1050.3(34)$ & 1059 \\
\hline 3-methyl-1H-tetrazol-3-ium-5-aminide (A) & $\gamma \mathrm{CH}_{3}^{\prime}$ & & $1044.4(100)$ & \\
\hline 3-methyl-1H-tetrazol-3-ium-5-aminide (A) & $v \mathrm{~N}_{(4)}-\mathrm{C}_{(5)}$ & 981.8 & $940.1(53)$ & \\
\hline & & 977.1 & & \\
\hline methyl azide & $\nu \mathrm{CN}$ & 892.1 & $896.0(20)$ & 905 \\
\hline & & 887.0 & & \\
\hline 3-methyl-1H-tetrazol-3-ium-5-aminide (A) & $\delta$ ring1 & 802.1 & $792.7(17)$ & \\
\hline & & 800.3 & & \\
\hline 1-methyl-1H-diazirene-3-amine & $\gamma \mathrm{N}(\mathrm{C}) \mathrm{NN}$ & $\sim 660$ & $654.2(13)$ & 660 \\
\hline methyl azide & $\delta \mathrm{NNN}$ & & $646.0(11)$ & \\
\hline 3-methyl-1H-tetrazol-3-ium-5-aminide (A) & $v \mathrm{~N}-\mathrm{C}\left(\mathrm{H}_{3}\right)$ & & $643.2(20)$ & \\
\hline 3-methyl-1H-tetrazol-3-ium-5-aminide (A) & $\gamma \mathrm{N}-\mathrm{H}_{(12)}$ & 453.9 & $451.1(99)$ & \\
\hline
\end{tabular}

${ }^{a}$ Key: $v$, stretching; $\delta$, bending; $\gamma$, rocking; $\omega$, wagging; s., symmetric; as., antisymmetric. ${ }^{b}$ DFT(B3LYP)/6-311++G(d,p) calculated values (scaled by 0.978 ) obtained in the present study. Numbers in parentheses are calculated intensities $\left(\mathrm{km} \mathrm{mol}^{-1}\right)$. ${ }^{c}$ Reference values correspond to previously reported experimental wavenumbers: cyanamide; ${ }^{45}$ methyl azide; ${ }^{43,44} \mathrm{HNC} ;{ }^{50}$ methylenimine. ${ }^{44,47-49}$ Note that the photoproducts are generated in the same matrix cage are interacting to each other; this leads to small, but measurable, differences in the observed wavenumbers, compared with those for the monomeric noninteracting compounds isolated in solid argon, here given as reference values. For 3-methyl-1Htetrazol-3-ium-5-aminide (A), the numbering of the atoms in the tetrazole ring follows that used for $2 \mathrm{MTA}$; $\mathrm{H}_{(11)}$ is the aminide hydrogen and $\mathrm{H}_{(12)}$ is the tetrazole-ring hydrogen (see Table S4, Supplementary Information, for definition of coordinates for this molecule). 


\section{MTA}

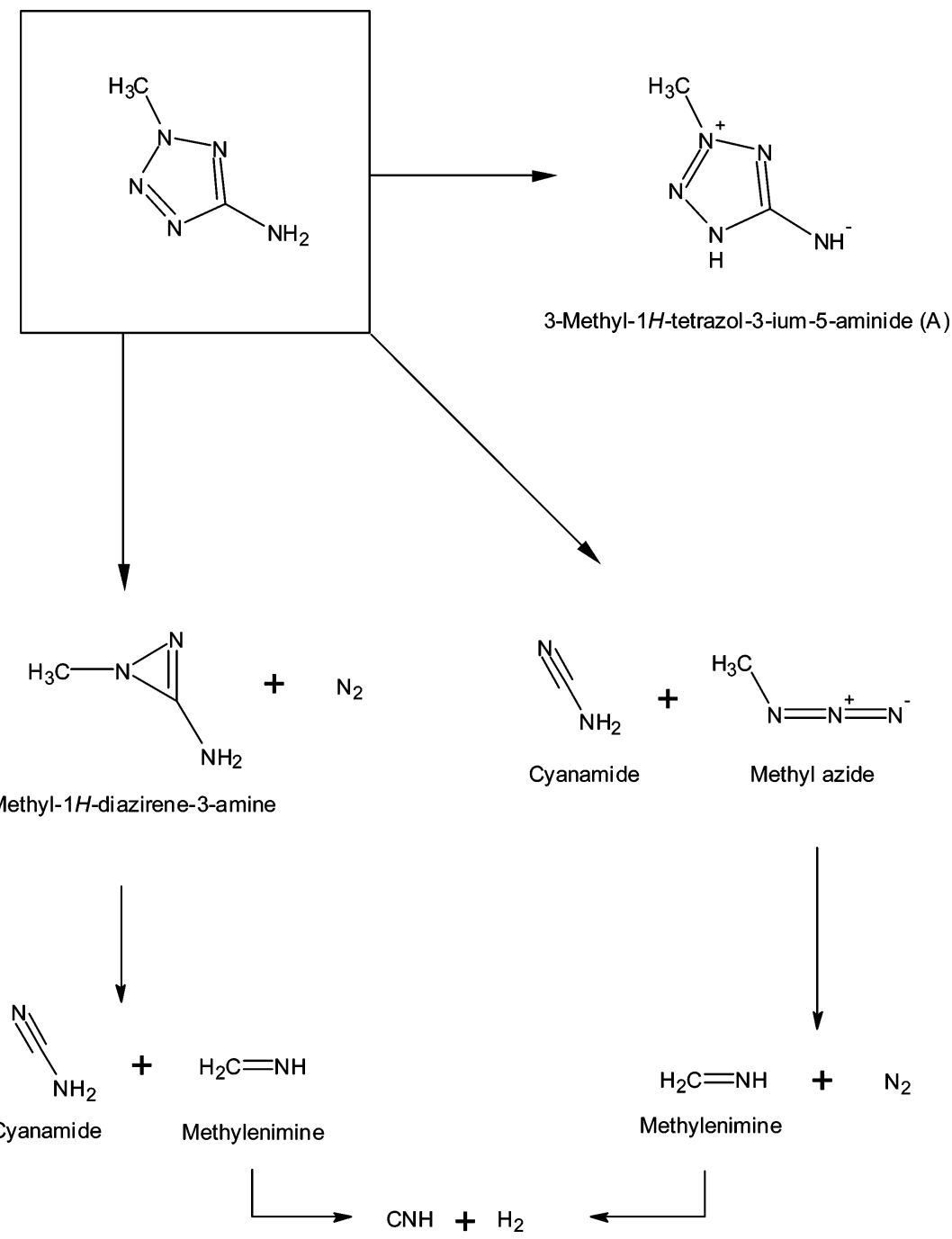

Figure 5. Scheme showing the observed photochemical processes.

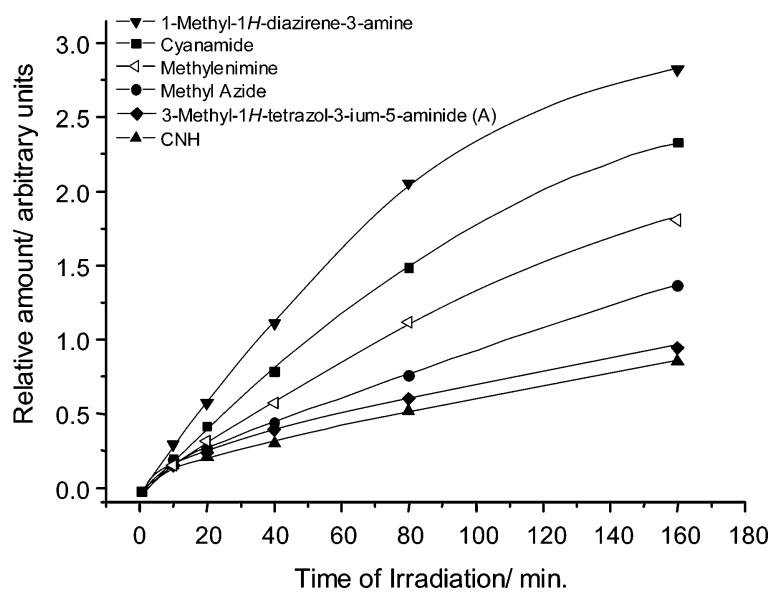

Figure 6. Variation with time of irradiation (min) of the absorbances of the characteristic bands of 2MTA photoproducts, normalized by the corresponding calculated (DFT(B3LYP)/6-311++G(d,p) intensities.

diazirene-3-amine is already small (see also Figure 4). The ring cleavage leading to production of methyl azide and cyanamide is considerably slower than the previously considered reaction and, after 180 min of irradiation, the amount of methyl azide continues to grow almost linearly with time (Figures 4 and 6). Finally, the slowest observed primary photoprocess corresponds to the tautomerization of 2MTA to mesoionic 3-methyl- $1 H$ tetrazol-3-ium-5-aminide. The fact that this last process is the slowest one among all observed processes may also indicate that 3-methyl-1H-tetrazol-3-ium-5-aminide is also being photoisomerized back to 2MTA.

\section{Conclusion}

2-Methyl-2H-tetrazol-5-amine (2MTA) was found to have a planar tetrazole ring, with both the methyl carbon and amine nitrogen atoms lying in the ring-plane and the amine group pyramidalized [the calculated $\mathrm{H}-\mathrm{N}(-\mathrm{C})-\mathrm{H}$ dihedral angle was predicted to be $135.9^{\circ}$ ]. The infrared spectrum of matrix-isolated 2MTA was fully assigned and correlated with structural properties, indicating that, in the matrixes, the amine group becomes slightly more planar than in the gas phase, due to matrix-packing effects. In situ UV-irradiation $(\lambda>235 \mathrm{~nm})$ of the matrix-isolated 2MTA monomer is shown to induce three main primary photochemical processes occurring at different rates: (1) tautomerization to mesoionic 3-methyl- $1 H$-tetrazol3-ium-5-aminide; (2) nitrogen elimination, with production of 1-methyl- $1 H$-diazirene-3-amine; (3) ring cleavage leading to production of methyl azide and cyanamide. Following the primary photoproducts, secondary reactions were observed, leading to spectroscopic observation of methylenimine and isocyanidric acid. 
Acknowledgment. We acknowledge the Portuguese Science Foundation (FCT. POCTI/QUI/58937/2004 and POCTI/59019/ 2004) and FEDER for financial support. A.G.-Z. thanks FCT also for the Grant SFRH/BPD/11499/2002, a well as CONICET and the Argentinian Agencia Nacional de Promoción Científica y Tecnológica (PICT 13080). I.D.R. acknowledges FCT for the Grant SFRH/BPD/1661/2000.

Supporting Information Available: Tables of optimized geometries, internal coordinators, and frequencies and intensities. This material is available free of charge via the Internet at http:// pubs.acs.org.

\section{References and Notes}

(1) Singh, H.; Chawla, A. S.; Kapoor, V. K.; Paul, D.; Malhotra, R. K., Prog. Med. Chem. 1980, 17, 151.

(2) Noda, K.; Saad, Y.; Kinoshita, A.; Boyle, T. P.; Graham, R. M.; Husain, A.; Karnik, S. S. J. Biol. Chem. 1995, 270, 2284.

(3) Mavromoustakos, T.; Kolocouris, A.; Zervou, M.; Roumelioti, P.; Matsoukas, J.; Weisemann, R. J. Med. Chem. 1999, 42, 1714.

(4) Toney, J. H.; Fitzgerald, P. M. D.; Groversharma, N.; Olson, S. H.; May, W. J.; Sundelof, J. G.; Vanderwall, D. E.; Cleary, K. A.; Grant, S. K.; Wu, J. K.; Kozarich, J. W.; Pompliano, D. L.; Hammond, G. G. Chem. Biol. 1998, 5, 185

(5) Hashimoto, Y.; Ohashi, R.; Kurosawa, Y.; Minami, K.; Kaji, H.; Hayashida, K.; Narita, H.; Murata, S. J. Cardiovasc. Pharm. 1998, 31, 568

(6) Desarro, A.; Ammendola, D.; Zappala, M.; Grasso, S.; Desarro, G. B. Antimicrobial Agents \& Chemotherapy 1995, 39, 232

(7) Tamura, Y.; Watanabe, F.; Nakatani, T.; Yasui, K.; Fuji, M.; Komurasaki, T.; Tsuzuki, H.; Maekawa, R.; Yoshioka, T.; Kawada, K.; Sugita, K.; Ohtani, M. J. Med. Chem. 1998, 41, 640.

(8) Abell, A. D.; Foulds, G. J. J. Chem. Soc. Perkin Trans. 1 1997, 17, 2475.

(9) Sandmann, G.; Schneider, C.; Boger, P. Z. Naturforsch. C 1996 51,534

(10) Koldobskii, G. I.; Ostrovskii, V. A.; Poplavskii, V. S. Khim. Geterotsikl. Soedin. 1981, 10, 1299.

(11) Zhao-Xu, C.; Heming, X. Int. J. Quantum Chem. 2000, 79, 350

(12) Jonassen, H. B.; Paukert, T.; Henry, R. A. Appl. Spectrosc. 1967, 21,89 .

(13) Lieber, E.; Levering, D. R.; Patterson, J. Anal. Chem. 1951, 23, 1594.

(14) Murphy, D. B.; Picard, J. P. J. Org. Chem. 1954, 19, 1807.

(15) Bugalho, S.; Maçôa, E.; Cristiano, L.; Fausto, R. Phys. Chem. Chem. Phys. 2001, 3, 3541 .

(16) Bugalho, S.; Serra, A.; Lapinski, L.; Cristiano, L.; Fausto, R. Phys. Chem. Chem. Phys. 2002, 4, 1725.

(17) Bugalho, S.; Lapinski, L.; Cristiano, L.; Frija, L.; Fausto, R. Vibrat. Spectrosc. 2002, 30, 213.

(18) Bats, J. W. Acta Crystallogr. B 1976, 32, 2866. 543.

(19) McCrone, W. C.; Grabar, D.; Lieber, E. Anal. Chem. 1957, 23,

(20) Putten, N. Vander; Heijdenrijk, D.; Schenk, H. Cryst. Struct. Commun. 1974, 3321.

(21) Goddard, R.; Heinemann, O.; Krüger, C. Acta Crystallogr. 1997, C53, 590 .
(22) Butler, R. N.; Garvin, V. C.; Lumbroso, H.; Liègeois, C. J. Chem. Soc. Perkin Trans. 2 1984, 721.

(23) Zhaoxu, C.; Heming, X. J. Mol. Struct.(Theochem.) 1998, 453, 65.

(24) Dunkin, I. R.; Shields, C. J.; Quast, H. Tetrahedron 1989, 45, 259.

(25) Chae, Y. B.; Chang, K. S.; Kim, S. S. The Daehan Hwak Hwoejee $1967,11,85$.

(26) Maier, G.; Eckwert, J.; Bothur, A.; Reisenauer, H. P.; Schmidt, C. Leibigs Ann. 1996, 1041

(27) Awadallah, A.; Kowski, K.; Rademacher, P. J. Heterocycl. Chem. 1997, 34, 113.

(28) Reva, I.; Stepanian, S.; Adamowicz, L.; Fausto, R. J. Phys. Chem. A 2001, 1054773.

(29) Frisch, M.; Trucks, G.; Schlegel, H.; Scuseria, G.; Robb, M.; Cheeseman, J.; Zakrzewski, V.; Montgomery, J.; Stratmann, R.; Burant, K.; Dapprich, S.; Millam, J.; Daniels, A.; Kudin, K.; Strain, M.; Farkas, O.; Tomasi, J.; Barone, V.; Cossi, M.; Cammi, R.; Mennucci, B.; Pomelli, C.; Adamo, C.; Clifford, S.; Ochterski, J.; Petersson, G.; Ayala, P.; Cui, Q.; Morokuma, K.; Malick, D.; Rabuck, A.; Raghavachari, K.; Foresman, J.; Cioslowski, J.; Ortiz, J.; Baboul, A.; Stefanov, B.; Liu, G.; Liashenko, A.; Piskorz, P.; Komaromi, I.; Gomperts, R.; Martin, R.; Fox, D.; Keith, T.; Al-Laham, M.; Peng, C.; Nanayakkara, A.; Challacombe, M.; Gill, P.; Johnson, B.; Chen, W.; Wong, M.; Andres, J.; Gonzalez, C.; Head-Gordon, M.; Replogle, S.; Pople, J., Gaussian 98, revision A.9, Gaussian Inc. Pittsburgh, PA 1998.

(30) Becke, A. D. Phys. Rev. A 1988, 38, 3098.

(31) Lee, C. T.; Yang, W. T.; Parr, R. G. Phys. Review B 1988, 37, 785.

(32) Csaszar, P.; Pulay, P. J. Mol. Struct.(Theochem.) 1984, 114, 31.

(33) Schachtschneider, J. H. Technical Report, Shell Development Co. Emeryville, CA, 1969.

(34) Michaut, X.; Vasserot, A.-M.; Abouaf-Marguin, L. Vibrat. Spectrosc. 2004, 3483 .

(35) Reva, I. D.; Stepanian, S. G.; Adamowicz, L.; Fausto, R. Chem. Phys. Lett. 2003, 374, 631.

(36) Reva, I. D.; Stepanian, S. G.; Adamowicz, L.; Fausto, R. J. Phys Chem. A 2003, 107, 6351.

(37) Lopes, S.; Gómez-Zavaglia, A.; Lapinski, L.; Chattopadhyay, N.; Fausto, R. J. Phys. Chem. A. 2004, 108, 8256.

(38) Quast, H.; Bieber, L. Angew. Chem. 1975, 87, 422.

(39) Quast, H.; Bieber, L. Chem. Ber. 1981, 1143253.

(40) Quast, H.; Nahr, U. Chem. Ber. 1985, 118, 526.

(41) Quast, H. Heterocycles 1980, 14, 1677.

(42) Quast, H.; Fuss, A.; Nahr, U. Chem. Ber. 1985, 118, 2164

(43) Zhizhong, W. J. Mol. Struct.(Theochem.) 1998, 434, 1.

(44) Milligan, D. E. J. Chem. Phys. 1961, 35, 1491.

(45) King, S. T.; Strope, J. H. J. Chem. Phys. 1971, 54, 1289.

(46) Nguyen, M. T.; Sengupta, D.; Ha, T.-K. J. Phys. Chem. 1996, 100, 6499.

(47) Nguyen, M. T. Chem. Phys. Lett. 1985, 117, 290.

(48) Jacox, M. E.; Milligan, D. E. J. Mol. Spectrosc. 1975, 56, 333

(49) Oliveira, G.; Martins, J. M. L.; Silwa, I. K. S.; Liebman, J. F. J. Comput. Chem. 2001, 22, 1297.

(50) Crovisier, J. BASEMOL - "Constants for Molecules of Astrophysics Interest in the Gas Phase: Photodissociation, Microwave and Infrared Spectra", Laboratoire d'études spatiales et d'instrumentation en astrophysique, Observatoire de Paris-Meudon, France. 2002. http://www. usr.obspm.fr/ $\sim$ crovisie/basemole/. 